\title{
One-year results of thoracic endovascular aortic repair for blunt thoracic aortic injury (RESCUE trial)
}

\author{
Ali Khoynezhad, MD, PhD, FACS, ${ }^{a}$ Carlos E. Donayre, MD, ${ }^{b}$ Ali Azizzadeh, MD, ${ }^{c}$ and \\ Rodney White, MD, ${ }^{b}$ on behalf of the RESCUE investigators
}

\begin{abstract}
Objective: One-year outcomes of the RESCUE trial (endovascular aortic repair using Valiant Captivia for blunt thoracic aortic injury) are reported.
\end{abstract}

\begin{abstract}
Methods: RESCUE is a prospective, nonrandomized, multicenter trial. Fifty patients with blunt thoracic aortic injury were enrolled between April 2010 and January 2012. One-year outcomes included secondary procedures, device-, procedure-, and/or aorta-related adverse events, and all-cause mortality.
\end{abstract}

\begin{abstract}
Results: Mean patient age was $40.7 \pm 17.4$ years; $76 \%$ of patients were male. Fifty-two thoracic stent grafts were implanted within a median of 1 day of injury. Seventy percent (35 of 50) of aortic injuries were grade III or higher, including 1 free rupture. The mean Injury Severity Score was $37.6 \pm 14.3$. Vascular access, device delivery, and deployment were successful in all patients. The left subclavian artery was completely covered in $40 \%$ (20 of 50) and partially covered in $18 \%$ of patients ( 9 of 50 ). There were no strokes or spinal cord injuries. Median procedure time was 90.5 minutes; median hospital stay was 11 days. All-cause mortality within 1 year was $12 \%$. There were no conversions to open repair. Four patients $(8 \%)$ had subclavian artery revascularization; 1 preoperatively; 3 others postoperatively on days 8,36 , and 103 . There were no device-related adverse events. During follow-up, 1 patient (2\%) had aortic-related and 9 patients (18\%) had procedure-related adverse events.

Conclusions: TEVAR has favorable early midterm outcomes in the treatment of blunt thoracic aortic injury, and remains the treatment modality of choice. Longevity of the stent grafts in this young patient population has yet to be established. (J Thorac Cardiovasc Surg 2015;149:155-61)
\end{abstract}

See related commentary on pages 161-2.

Supplemental material is available online.

From the Division of Cardiothoracic Surgery, ${ }^{a}$ Cedars-Sinai Medical Center, Los Angeles, Calif; The Harbor-UCLA Medical Center, ${ }^{\mathrm{b}}$ Torrance, Calif; and Memorial Hermann Heart and Vascular Institute, ${ }^{\mathrm{c}}$ University of Texas Medical Center, Houston, Tex.

Disclosures: The study was sponsored by Medtronic Endovascular Therapies. The authors had control of the design of the study, methods used, outcome parameters and results, data analysis, and generation of the written report. Working under direction from A.K., Matt Groesbeck, MPH, and Judith Greengard, PhD, independent consultants for the sponsor, and Victoria Rendon, an employee of the sponsor, drafted the methods and results sections and prepared the figures and tables. Yuqing $\mathrm{Dai}, \mathrm{PhD}$, an employee of the sponsor, performed all statistical analyses and confirmed data accuracy. A. Azizzadeh, C.E. Donayre, A. Khoynezhad, and R. White are consultants of Medtronic Endovascular Therapies, serving in physician training programs sponsored by Medtronic. A. Khoynezhad is also a consultant to W.L. Gore. R. White is also a consultant to Endologix, Gore Medical, and Volcano Corporation.

Read at the 40th Annual Meeting of The Western Thoracic Surgical Association, Dana Point, California, June 25-28, 2014.

A complete list of the RESCUE investigators can be found in Appendix E2.

Received for publication June 24, 2014; revisions received Sept 2, 2014; accepted for publication Sept 10, 2014; available ahead of print Oct 27, 2014.

Address for reprints: Ali Khoynezhad, MD, PhD, FACS, Cedars-Sinai Heart Institute, 127 S. San Vicente Blvd, Suite A3306, Los Angeles, CA 90048 (E-mail: akhoy@ cshs.org).

0022-5223/\$36.00

Copyright $\odot 2015$ by The American Association for Thoracic Surgery

http://dx.doi.org/10.1016/j.jtcvs.2014.09.026
Blunt thoracic aortic injury (BTAI) is caused by abrupt deceleration during a motor vehicle or motorcycle crash, a fall from a significant height, or other traumatic accidents. BTAI is the second leading cause of death in the United States from nonpenetrating trauma, with an estimated incidence of 7500 to 8000 cases per year. ${ }^{1}$ Up to $85 \%$ of patients involved in such incidents die before hospitalization. ${ }^{2}$ A meta-analysis in 2011 reported that in-hospital mortality of patients managed nonoperatively was as high as $46 \%$, whereas mortality was $9 \%$ in patients treated by endovascular repair and $19 \%$ for open repair. ${ }^{3}$

In the past decade, thoracic endovascular aneurysm repair (TEVAR) has become an approach preferred by many clinicians for patients with BTAI because of its favorable early outcomes compared with open repair and nonoperative management in single-center series. ${ }^{4-8}$ TEVAR offers several advantages in the treatment of BTAI in addition to low morbidity and mortality, particularly in the context of the delivery of acute trauma care and the treatment of multiple traumatic injuries. ${ }^{9}$ TEVAR is useful as a bridging or definitive therapy. Patient stabilization allows other competing traumatic injuries to be addressed. TEVAR is a rapid procedure that does not involve thoracotomy or lengthy complicated anesthesia and requires less blood transfusion than open repair. ${ }^{3}$ In single-center series, the risk of paraplegia has 


\section{Abbreviations and Acronyms \\ BTAI = blunt thoracic aortic injury \\ CEC = Clinical Events Committee \\ $\mathrm{CT}=$ computed tomography \\ CTA = computed tomographic angiography \\ CVA $=$ cerebral vascular accident \\ ISS = Injury Severity Score \\ LSA = left subclavian artery \\ MRI = magnetic resonance imaging \\ TEVAR $=$ thoracic endovascular aneurysm repair \\ RESCUE $=$ Performancee of the Valiant Thoracic \\ Stent Graft With the Captivia Delivery \\ System for the Endovascular Treatment of BTAI}

also been reported to be reduced with TEVAR with rates of $0 \%$ to $2 \%$, compared with $5 \%$ to $10 \%$ or more with open repair techniques. ${ }^{4,10-13}$

Significant challenges remain regarding the mid- to long-term durability and longevity of TEVAR stent graft technology and the propensity for complications such as endoleak, migration, and device collapse and failure, along with the technical constraints associated with diameter sizing, coverage of the left subclavian artery (LSA), and access issues. Follow-up surveillance can also be problematic, and the requirements for early-to-midterm follow-up of patients who have undergone TEVAR for BTAI are poorly understood. ${ }^{3}$

The purpose of the RESCUE Trial (Performancee of the Valiant Thoracic Stent-Graft With the Captivia Delivery System [Medtronic, Inc, Minneapolis, Minn] for the Endovascular Treatment of BTAI) is to capture and report TEVAR outcomes for BTAI for up to 5 years. This report focuses on outcomes from the first year of the RESCUE trial.

\section{METHODS}

The RESCUE trial is a prospective, nonrandomized, North American multicenter trial of the Valiant Captivia Thoracic Stent-Graft System for the treatment of BTAI (ClinicalTrials.gov: NCT01092767). A total of 69 patients were screened for enrollment between April 14, 2010, and January 17, 2012, at 25 investigational sites. Ultimately, 50 patients were enrolled across 20 sites (19 sites in the United States and 1 in Canada), most of which were affiliated with level I trauma centers. The clinical backgrounds of the investigators included cardiothoracic surgery, vascular surgery, and interventional radiology.

In 2013, we published the 30-day outcomes for both the primary and secondary end points from the RESCUE trial. ${ }^{14}$ The primary study end point in that report was 30-day all-cause mortality. Secondary end points included 30-day technical success, procedural/aortic injury-related adverse events, and aortic injury-related mortality. The current report focuses on the outcomes beyond 30 days and up to the first year of follow-up, specifically, secondary procedures, device-, procedure-, and aortic-related serious adverse events, and all-cause mortality.
The trial was designed by the principal investigators and the sponsor. Data were collected by the sponsor. Before the trial was initiated, the RESCUE protocol and patient informed consent form were reviewed and approved by an appropriately constituted Institutional Review Board at each clinical site in the United States and by the Research Ethics Board at the Canadian site. All imaging analysis was performed by an independent core laboratory (M2S, Inc, West Lebanon, NH). Deaths were adjudicated by an independent Clinical Events Committee (CEC) at Harvard Clinical Research Institute (Boston, Mass), which also coordinated an independent data monitoring committee that reviewed adverse events associated with a death. The investigator determined relatedness for nonfatal adverse events. The first author prepared the first draft, which was then reviewed and edited by the other coauthors. The sponsor had the right to review but not to approve the final manuscript. The authors had full access to all data, accept full responsibility for the accuracy and completeness of the reported analyses and interpretations of the data, and vouch for the fidelity of the study to the protocol.

\section{Inclusion Criteria}

For inclusion, patients were required to be 18 years of age or older with informed consent offered through an Investigational Device Exemption approved by the US Food and Drug Administration or an Investigational Testing Authorization approved by Health Canada. Patients with BTAI were identified by preoperative computed tomographic angiography (CTA). The injury was confirmed by angiography or intravascular ultrasonography at the time of the procedure. The patient's aortic diameter (adventitia to adventitia) of the proximal and distal landing zones were required to be 18 to $44 \mathrm{~mm}$. Iliac or femoral arteries were required to have sufficient diameter and patency to be used as access vessels as determined by computed tomography (CT) or the patient had to be deemed eligible for an iliac conduit. The distance between the distal margins of the left common carotid artery to the intimal disruption on center-of-flow imaging reconstruction was required to be $20 \mathrm{~mm}$ or more. Patients were also required to have undergone TEVAR within 30 days of injury.

\section{Exclusion Criteria}

Patients were excluded if they sustained a nonsurvivable injury/condition or if their Injury Severity Score (ISS) was nonspecific. Patients were also excluded if the covered portion of the stent graft cloth was planned to be placed over the celiac artery or the left common carotid artery (or the innominate artery in a case of bovine arch); if the patient presented with systemic infection or pregnancy, had a history of cerebral vascular accident (CVA) within 2 months before intervention, had a bleeding diathesis or coagulopathy, a known hypersensitivity or contraindication to anticoagulants or contrast media, allergy to the device components, a previous descending thoracic aortic intervention or operation, or participation in conflicting investigational drug or device clinical trials. Connective tissue disorders were not exclusory; inclusion of all emergency patients was deemed to more closely represent real-world clinical experience.

\section{Definitions}

We used the classification system described by Azizzadeh and colleagues in $2009^{15}$ to define the extent of BTAI. Tears confined to the intima were classified as grade I, intramural hematomas as grade II, aortic pseudoaneurysms as grade III, and free ruptures as grade IV. The ISS overall score was used to describe a patient's probability of death due to multiple injuries. ${ }^{16}$

\section{Follow-up}

The RESCUE trial follows survivors at intervals of 1,6 , and 12 months and annually thereafter for 5 years. Physical examination, adverse event evaluation, and CTA or magnetic resonance angiography are performed at each visit. Multiple-view chest radiographs are also acquired at 1, 3, and 5 years to assess device integrity. 


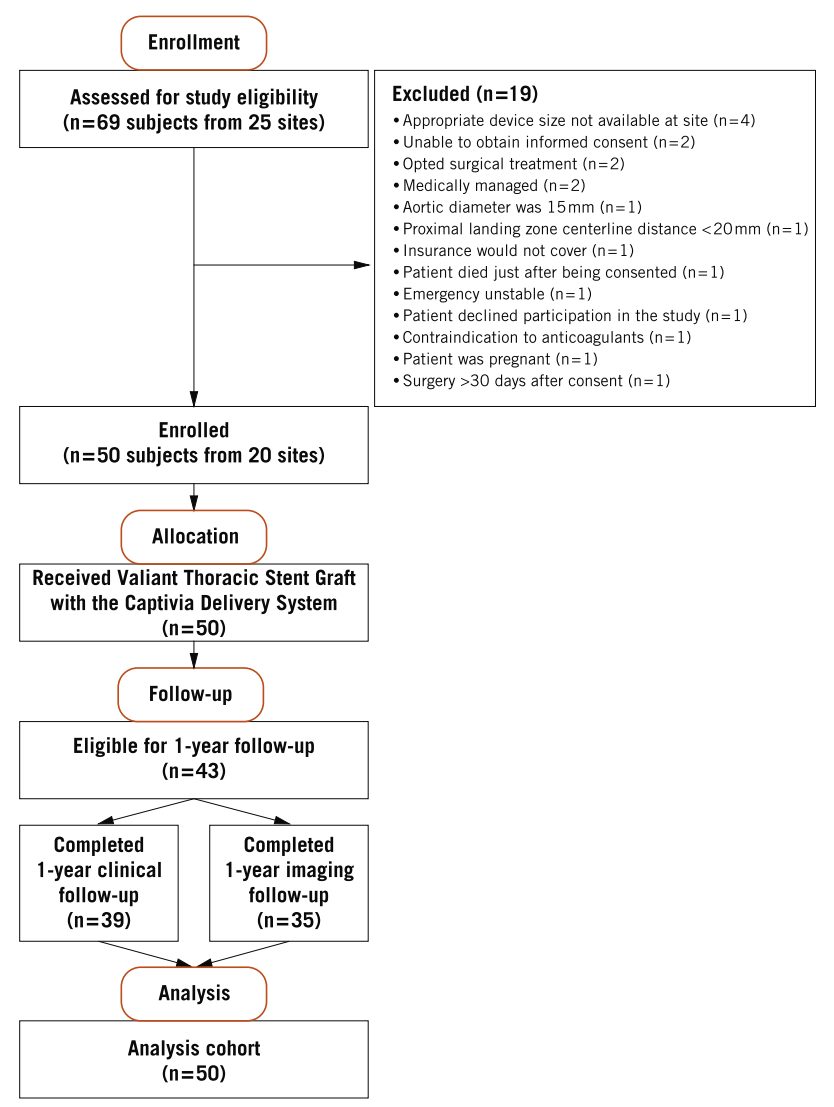

FIGURE 1. Patient CONSORT diagram.

\section{Statistical Methods}

For categorical variables, frequency and percentages are presented using descriptive statistics. For continuous variables, the number of observations, mean, standard deviation, median, minimum, and maximum are presented. Kaplan-Meier curves and log-rank tests were used to analyze the time to event for each survival outcome (all-cause and aortic-related mortality). Statistical significance was assessed by the log-rank statistic $(\alpha=0.05)$. Outcome events were summarized at prespecified time points: within 30 days, within 1 year, and/or between 30 days and 1 year. Study data were analyzed using Statistical Analysis Software v. 9.2 (SAS Institute, Inc, Cary, NC).

\section{RESULTS}

Of 69 screened patients, 50 were enrolled across 20 sites in the United States and Canada (Figure 1). ${ }^{14}$ All patients successfully received at least 1 device to cover the site of injury. No device malfunctions were reported. Two patients received 2 stent grafts each; all others received a single device. The first of these received 2 Valiant Captivia thoracic stent grafts, each $100 \mathrm{~mm}$ long. The second patient received a proximal Valiant Captivia stent graft and a distal Talent stent graft (Medtronic, Inc). Thirty-nine (90.7\%) of the 43 eligible patients completed clinical follow-up and 35 $(81.4 \%)$ underwent imaging at the 1-year time point.

\section{Patient Population}

Baseline demographic characteristics and medical history of all 50 patients are presented in Table 1 . The
TABLE 1. Baseline demographic characteristics

\begin{tabular}{lc}
\hline \multicolumn{1}{c}{ Characteristic } & Value \\
\hline Age, $y$ & \\
Mean \pm SD & $40.7 \pm 17.4$ \\
Median (range) & $39.5(18-76)$ \\
Male, $\%$ & $76(38$ of 50$)$ \\
Ethnicity, \% & \\
Hispanic or Latino & $20(10$ of 50$)$ \\
Race, $\%$ & \\
White & $68(34$ of 50$)$ \\
Black or African American & $20(10$ of 50$)$ \\
Asian & $4(2$ of 50$)$ \\
Other & $4.0(2$ of 50$)$ \\
Not available & $4.0(2$ of 50$)$ \\
Medical history, \%* & \\
Hypertension & $24.5(12$ of 49$)$ \\
Chronic obstructive pulmonary disease & $4.1(2$ of 49$)$ \\
Gastrointestinal conditions & $2.1(1$ of 48$)$ \\
Paraplegia & $2.0(1$ of 49$)$ \\
Congestive heart failure & $2.0(1$ of 49$)$ \\
Diabetes & $2.0(1$ of 49$)$ \\
Stroke & $0.0(0$ of 49$)$ \\
Renal insufficiency & $0.0(0$ of 49$)$ \\
Myocardial infarction & $0.0(0$ of 49$)$ \\
Other conditions & $46.0(23$ of 50$)$ \\
\hline
\end{tabular}

$S D$, Standard deviation. *Site-reported medical history; 1 patient (no. 182-001) died from injuries before answering medical history questions; 1 patient's (no. 325-003) gastrointestinal condition was listed as unknown.

mean age was $41 \pm 17$ years (range, $18-76$ years); $76 \%$ (38 of 50) were male. The most commonly reported preexisting condition was hypertension $(24 \%)$. Although 23 of 50 patients $(46 \%)$ were reported to have other preexisting conditions, only 3 of these were cardiovascular related ( 2 with atrial fibrillation; 1 with an ascending aortic aneurysm). Preoperative paraplegia was reported in 1 patient and was attributed to a spinal fracture sustained in the traumatic event.

The injury characteristics are presented in Table 2. Most of the injuries were caused by a motor vehicle collision $(60 \%)$ or a motorcycle incident $(22 \%)$. Mean ISS was 38 \pm 14 (range, 13-75). Most patients sustained grade III or grade IV injuries $(70 \%)$. Most BTAIs $(84 \% ; 42$ of 50 ) occurred in the proximal descending thoracic aorta (aortic isthmus); the remaining $16 \%$ (8 of 50) of patients sustained aortic injuries located in the distal half of the descending thoracic aorta. The anatomic characteristics are presented in Table E1 and were described previously. ${ }^{14}$

\section{Procedural Data}

Fifty-one Medtronic Valiant Captivia thoracic stent grafts and 1 Talent thoracic stent graft were successfully implanted in 50 patients. Stent graft implantation was performed within a median of 1 day after injury (mean $1.8 \pm 4.0$ days; range, $0-23$ days). General anesthesia was used in all 50 patients. The median duration of the 
TABLE 2. Baseline injury characteristics

\begin{tabular}{|c|c|}
\hline Characteristic & Value \\
\hline \multicolumn{2}{|l|}{ Duration from injury to procedure, $\mathrm{d}$} \\
\hline Mean \pm SD & $1.8 \pm 4.0$ \\
\hline Median (range) & $1.0(0-23)$ \\
\hline \multicolumn{2}{|l|}{ Mechanism of blunt injury, $\%$} \\
\hline Motor vehicle accident & $60.0(30$ of 50$)$ \\
\hline Motorcycle accident & $22.0(11$ of 50$)$ \\
\hline Pedestrian hit by motor vehicle & $10.0(5$ of 50$)$ \\
\hline Fall & $4.0(2$ of 50$)$ \\
\hline Other & $4.0(2$ of 50$)$ \\
\hline \multicolumn{2}{|l|}{ Extent of overall injuries } \\
\hline \multicolumn{2}{|l|}{ Assigned Injury Severity Score } \\
\hline Mean \pm SD & $38.4 \pm 14.4$ \\
\hline Median (range) & $35.0(13-75)$ \\
\hline \multicolumn{2}{|l|}{ Extent of aortic injury, \%* } \\
\hline Grade I: intimal tear & $18(9$ of 50$)$ \\
\hline Grade II: intramural hematoma & $12(6$ of 50$)$ \\
\hline Grade III: aortic pseudoaneurysm & $68(34$ of 50$)$ \\
\hline Grade IV: free rupture & $2(1$ of 50$)$ \\
\hline \multicolumn{2}{|l|}{ Associated traumatic injuries, $\%$} \\
\hline Lung injury & $70(35$ of 50$)$ \\
\hline Rib fracture & $64(32$ of 50$)$ \\
\hline $\begin{array}{l}\text { Abdominal injury (solid organ, bowel, bladder, } \\
\text { or diaphragm injury) }\end{array}$ & $58(29$ of 50$)$ \\
\hline Other & $50(25$ of 50$)$ \\
\hline Head injury & $48(24$ of 50$)$ \\
\hline Pelvic fracture & $40(20$ of 50$)$ \\
\hline Long bone fracture & $38(19$ of 50$)$ \\
\hline Unstable $\mathrm{C} / \mathrm{T} / \mathrm{L}$ spine fractures & $14(7$ of 50$)$ \\
\hline Neurologic deficits & $12(6$ of 50$)$ \\
\hline Scapula fracture & $8(4$ of 50$)$ \\
\hline Sternum fracture & $6(3$ of 50$)$ \\
\hline \multicolumn{2}{|l|}{ Location of aortic injury, $\%$} \\
\hline $\begin{array}{l}\text { Isthmus (just distal to the left subclavian } \\
\text { artery to the third intercostals artery) }\end{array}$ & $84(42$ of 50$)$ \\
\hline Distal descending thoracic aorta & $16(8$ of 50$)$ \\
\hline
\end{tabular}

procedure was 90.5 minutes (mean $102 \pm 57.0$ minutes). The median time in intensive care from admission to discharge was 6 days (mean $10.4 \pm 16.2$ days).

The proximal stent graft piece was most commonly implanted in zone $2(58 \% ; 29$ of 50$)$, followed by zone 3 $(36 \% ; 18$ of 50$)$, zone $4(4 \% ; 2$ of 50$)$, and zone 1 $(2.0 \% ; 1$ of 50$)$. A proximal FreeFlo stent graft was used in all cases except 1 where a closed web tapered graft was mistakenly substituted; no complications were attributed to this.

Technical success with regard to device access, delivery, and deployment was $100 \%$. No conversions to open repair were needed and no retrograde type A dissections or aortic perforations were reported. The LSA was completely covered in $40 \%$ (20 of 50) of patients and partially covered
TABLE 3. Study outcomes within 30 days and 1 year

\begin{tabular}{|c|c|c|}
\hline Outcomes & $\begin{array}{l}\text { Within } \\
\text { 30 days }\end{array}$ & $\begin{array}{l}\text { Within } \\
1 \text { year }\end{array}$ \\
\hline \multicolumn{3}{|l|}{ Secondary procedures } \\
\hline $\begin{array}{l}\text { Secondary endovascular } \\
\text { reinterventions }\end{array}$ & 0 & 0 \\
\hline Conversion to open repair & 0 & 0 \\
\hline LSA bypass & 1 & 2 \\
\hline \multicolumn{3}{|l|}{ Adverse events $(\%)$ related to } \\
\hline Device & 0 & 0 \\
\hline Procedure, and/or & $12(6$ of 50$)$ & $6.5(3$ of 46$)$ \\
\hline Aorta & $2.0(1$ of 50$)$ & 0 \\
\hline \multicolumn{3}{|l|}{ Mortality, $\%$} \\
\hline All-cause mortality & $8(4$ of 50$)$ & $12(6$ of 50$)$ \\
\hline Aorta-related mortality & $4(2$ of 50$)$ & $4(2$ of 50$)$ \\
\hline \multicolumn{3}{|l|}{ Technical success, $\%$} \\
\hline $\begin{array}{l}\text { Successful delivery and deployment } \\
\text { of the stent graft }\end{array}$ & $100(50$ of 50$)$ & NA \\
\hline Endoleak & 0 & 0 \\
\hline \multicolumn{3}{|l|}{ Stent graft failure } \\
\hline Kinking & 0 & 0 \\
\hline Twisting & 0 & 0 \\
\hline Fracture & 0 & 0 \\
\hline Loss of patency & 0 & 0 \\
\hline Migration* $>10 \mathrm{~mm}$ & NA & $2.9(1 \text { of } 34)^{*}$ \\
\hline
\end{tabular}

$\overline{L S A}$, Left subclavian artery; $N A$, not applicable. *The core laboratory reported 1 patient of 34 evaluable had a stent graft that migrated more than $10 \mathrm{~mm}$ beyond 30 days. Migration imaging only available from 30 days.

in $18 \%$ (9 of 50 ). The LSA required revascularization in $8 \%$ (4 of 50) of patients.

\section{One-Year Outcomes}

Secondary procedures. Within the first year, there were no secondary endovascular procedures or conversions to open repair (Table 3). However, 3 patients required LSA bypass to correct intermittent left arm ischemia on days 8 , 36 , and 103 , respectively. All 3 of these bypasses were adjudicated to be procedure-related (Table E2).

Device, procedure, and/or aortic-related serious adverse events (nonfatal). There were no device-related adverse events. There were 9 procedure-related adverse events reported in 8 patients within the first year $(6$ procedurerelated events in the first 30 days after the index procedure, and 3 between 30 days and 1 year). Two of these events were upper left arm peripheral ischemia, reported in patients 325-002 and 344-002, both of whom had intentional LSA coverage without previous revascularization. In addition, 2 patients who experienced claudication or no palpable radial pulse in the left arm also had intentional LSA coverage without previous revascularization. Four procedure-related events comprised confirmed injuries at the access sites: groin hematoma in patient 340-001, groin erythema in patient 325-003, femoral artery focal dissection in patient $005-003$, and iliac vein laceration in 


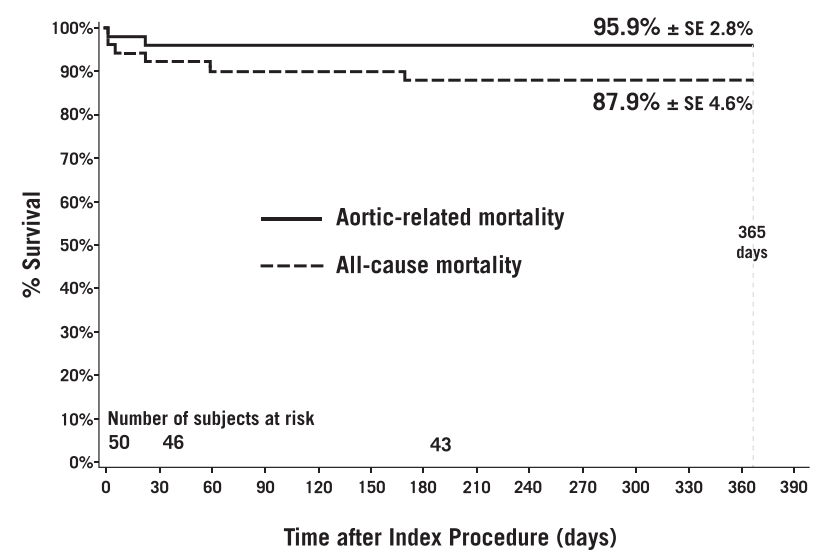

FIGURE 2. Kaplan-Meier estimate for all-cause mortality and aorticrelated mortality. $S E$, Standard error.

patient 340-004 (Table E3). There was 1 site-reported aortic-related adverse event. Patient 340-004 developed anoxic brain injury caused by preoperative hypotension on the day of the procedure without spinal cord injury or reported CVA. Events are further described in Table E3.

Technical observations. During follow-up in the first year, no endoleaks were reported by the core laboratory or the sites, which reviewed the intra and postoperative imaging of all patients. In addition, no stent grafts were reported to kink, twist, fracture, or lose patency or integrity. Two type II endoleaks were reported by the end of the index procedure, both of which had resolved without treatment by the 30-day visit. The sites reported no cases of device migration within the aorta.

All-cause mortality. Within the first year, $6(12 \%)$ patients died of any cause, 4 of whom $(8 \%)$ died within the first 30 days after the index procedure (Table E4). Of these 4 deaths, 2 (182-001 and 344-003) were adjudicated by the CEC as not related to the device, procedure, and/or to the aorta. The death of patient 018-001 due to a right-sided hemothorax on postoperative day 1 was adjudicated by the CEC as aorta related. Because of the undocumented nature of the cause of death of patient 059-002 on day 22 outside the hospital, it was adjudicated as related to the procedure, the device, and the aorta. There were 2 deaths beyond 30 days (patient 339-003 died on day 59; 340-004 on day 169), both of whom had a total ISS score of 38. The CEC adjudicated both as unrelated to the device, the procedure, and/or to the aorta. The death of 2 patients ( $4 \%$ of all patients) within 30 days was adjudicated as aorta-related mortality. The circumstances of each patient's death are detailed in Table E4 and Appendix E1. Kaplan-Meier estimates of all-cause and aortic-related survival are presented in Figure 2.

\section{DISCUSSION}

The RESCUE trial was designed to evaluate the outcomes of TEVAR for BTAI during a follow-up period of up to 5 years. In the past decade, the risk of paraplegia, a devastating complication, has been reported to be significantly reduced with TEVAR compared with open repair. ${ }^{4,10-13}$ The reduced rate of spinal cord injury is most probably due to lack of aortic crossclamping with subsequent hypoperfusion of the spinal cord artery. In the present 1-year interim study, the rate of paraplegia or paraperesis was $0 \%$. In addition, there were no CVAs, which may be attributed to the experienced team of investigators. Furthermore, the overall incidence of adverse events was favorably low: there were 9 procedure-related adverse events in 8 patients within the first year, 6 of which occurred in the first 30 days. The technical success rate was $100 \%$, comparable with the literature reports of $96.5 \%$ to $100 \%{ }^{17,18}$ Furthermore, there were no misaligned deployments, aortic perforations, retrograde type A dissections, conversions to open surgery, or endoleaks observed over the 1-year follow-up period, substantiating the safety of the newer generation of stent grafts.

RESCUE's previously reported 30-day all-cause mortality of $8 \%$ compares favorably with the $13 \%$ early mortality rate reported in the 2008 American Association for the Surgery of Trauma trial, ${ }^{4}$ and is comparable with the $6 \%$ to $10 \% 30$-day all-cause mortality found elsewhere in the literature. ${ }^{12,13,18-20}$ The current 1-year data continue to support this, with a cumulative 1-year all-cause mortality rate of $12 \%$ compared with $14.4 \%$ in the literature. ${ }^{18}$

There were no cases of device migration reported by the sites. However, 1 case of distal migration was reported by the core laboratory. The definition of migration of a thoracic endograft used by the core laboratory in this study was a change in centerline measurement from an adjacent artery branch to the top or bottom of the stent and is the standard for aneurysm reporting. Because migration was reported at only 1 end and there was no change in the span of the device, the observation is more suggestive of aortic lengthening rather than true migration. There were no clinical sequelae or interventions as a result of the reported apparent migration of the device.

Aortic dilatation is another potential late complication. In a series of patients with BTAI and stent graft implantation, aortic dilatation of $0.84 \mathrm{~mm} / \mathrm{y}$ at the stented zone was reported during a mean of 2.6 years follow-up (range, 1-5.5 years). ${ }^{21}$ The authors concluded that such dilatation is likely a result of the injury itself in combination with the radial force of the stent graft. ${ }^{21}$ In follow-up imaging in the RESCUE trial, no cases of aortic dilatation were observed. Long-term clinical follow-up after TEVAR in patients with BTAI, however, remains critical to the evaluation, and will be addressed in a subsequent study.

Questions remain as to whether imaging itself could lead to complications of BTAI, with controversy on the optimal frequency and whether imaging is best performed by CT or 
magnetic resonance imaging (MRI). A single chest CT scan subjects the human body to an estimated average dose of $7 \mathrm{mSv}$ of ionizing radiation (range, $4-18 \mathrm{mSv}$ ). ${ }^{22}$ A single exposure of $10 \mathrm{mSv}$ leads to cancer at a frequency of $1 / 1000 .^{23}$ A 40 -year-old trauma patient may live 30 years; the cumulative radiation dose from annual follow-up of $210 \mathrm{mSv}$ significantly increases the risk of malignancy. ${ }^{24}$ The most recent clinical practice guidelines of the Society for Vascular Surgery ${ }^{3}$ report that opinions among committee members "varied widely" regarding imaging frequency and type, leaving no clear-cut guideline for follow-up imaging. Rimon and colleagues ${ }^{25}$ reviewed 33 CTA examinations of 7 patients over a mean follow-up of 6.3 years. All stent grafts remained stable and devoid of complications. Over that time period, the average dose of radiation was $77 \mathrm{mSv}$ (range, $34-129 \mathrm{mSv}$ ), which is likely an underestimation of the total radiation dose as it excluded acute-phase CTAs performed in the emergency department. The authors concluded that, given the durability of modern endovascular devices, routine CTA is not warranted and should be avoided after the initial years of follow-up. ${ }^{25}$ Imaging modalities such as magnetic resonance angiography or time-of-flight MRI are valuable alternatives and should be strongly considered after the initial confirmatory CT scan. Including these in the postoperative surveillance protocol presents an opportunity to curtail radiation and nephrotoxic contrast administration.

\section{Limitations}

RESCUE is a nonrandomized, single-arm, multicenter investigation reported with descriptive statistics only. Timing of TEVAR relative to operations for accompanying injuries was at the discretion of the trauma surgeons and the investigators. The 1-year data provide limited midterm experience obtained at high-volume sites with highly experienced investigators in North America. Although these 1-year results extend our understanding of device durability in this patient cohort past the initial 30-day experience previously published, further follow-up is critical. There are practical issues in following trauma patients, and RESCUE was not immune to loss to follow-up. At 1 year, accountability of clinical follow-up was $90.7 \%$ (39 of 43 ) and imaging accountability was $81.4 \%$ (35 of 43 ) in the same timeframe. Poor follow-up in this population is commonly reported and has been associated with poor socioeconomic status, lack of health insurance, and lack of family support. ${ }^{26}$ Without proper follow-up, rare but serious complications, such as aortic thrombus or retrograde type A aortic dissection, can be missed, precluding effective and life-saving interventions. ${ }^{26,27}$

The treatment of patients with grade I BTAI with TEVAR is somewhat controversial. The natural history of grade I to II BTAIs shows that, although progression through higher grades up to and including death is possible, it is rare (roughly $5 \%$ ), as reported by Osgood and colleagues ${ }^{28}$ in a subgroup of 49 patients with BTAI. Based on these data, clinical practice guidelines of the Society for Vascular Surgery recommend conservative management of grade I BTAI except in a subset of patients with head injuries in whom increased cerebral perfusion pressure is requested by neurosurgical colleagues. The inclusion of these patients in the RESCUE trial reflects the practice preference of many clinicians who opt for early treatment, particularly in patients with head injuries but also expresses clinician uncertainty on BTAI progression and related markers.

\section{CONCLUSIONS}

TEVAR for BTAI with the Medtronic Valiant Captivia device showed that the safety and stent graft durability reported at 30 days was continued during 1 year of follow-up. The results demonstrate favorable midterm outcomes with very low rates of adverse events and mortality rates comparable with those in the literature. TEVAR should remain the treatment modality of choice in anatomically suitable patients with BTAI and grade II and higher aortic injury. Follow-up of this patient cohort remains challenging, and the durability and longevity of the stent grafts in this young patient population has yet to be established.

\section{References}

1. Smith RS, Chang FC. Traumatic rupture of the aorta: still a lethal injury. Am J Surg. 1986;152:660-3.

2. Teixeira PG, Inaba K, Barmparas G, Georgiou C, Toms C, Noguchi TT, et al Blunt thoracic aortic injuries: an autopsy study. J Trauma. 2011;70:197-202.

3. Lee WA, Matsumura JS, Mitchell RS, Farber MA, Greenberg RK, Azizzadeh A, et al. Endovascular repair of traumatic thoracic aortic injury: clinical practice guidelines of the Society for Vascular Surgery. J Vasc Surg. 2011;53:187-92.

4. Demetriades D, Velmahos GC, Scalea TM, Jurkovich GJ, Karmy-Jones R, Teixeira PG, et al. Diagnosis and treatment of blunt thoracic aortic injuries: changing perspectives. J Trauma. 2008;64:1415-8; discussion 18-19.

5. Dunham MB, Zygun D, Petrasek P, Kortbeek JB, Karmy-Jones R, Moore RD. Endovascular stent grafts for acute blunt aortic injury. J Trauma. 2004;56: 1173-8.

6. Lawlor DK, Ott M, Forbes TL, Kribs S, Harris KA, DeRose G. Endovascular management of traumatic thoracic aortic injuries. Can J Surg. 2005;48:293-7.

7. Neschis DG, Scalea TM, Flinn WR, Griffith BP. Blunt aortic injury. N Engl J Med. 2008;359:1708-16.

8. Mirvis SE, Shanmuganathan K. Diagnosis of blunt traumatic aortic injury 2007 still a nemesis. Eur J Radiol. 2007;64:27-40.

9. Neschis DG, Moainie S, Flinn WR, Scalea TM, Bartlett ST, Griffith BP. Endograft repair of traumatic aortic injury-a technique in evolution: A single institution's experience. Ann Surg. 2009;250:377-82.

10. Doss M, Wood JP, Balzer J, Martens S, Deschka H, Moritz A. Emergency endovascular interventions for acute thoracic aortic rupture: Four-year follow-up. J Thorac Cardiovasc Surg. 2005;129:645-51.

11. Fabian TC. Roger T. Sherman lecture. Advances in the management of blunt thoracic aortic injury: Parmley to the present. Am Surg. 2009;75:273-8.

12. Tang GL, Tehrani HY, Usman A, Katariya K, Otero C, Perez E, et al. Reduced mortality, paraplegia, and stroke with stent graft repair of blunt aortic transections: a modern meta-analysis. J Vasc Surg. 2008;47:671-5.

13. Xenos ES, Abedi NN, Davenport DL, Minion DJ, Hamdallah O, Sorial EE, et al Meta-analysis of endovascular vs open repair for traumatic descending thoracic aortic rupture. J Vasc Surg. 2008;48:1343-51. 
14. Khoynezhad A, Azizzadeh A, Donayre CE, Matsumoto A, Velazquez O, White R, et al. Results of a multicenter, prospective trial of thoracic endovascular aortic repair for blunt thoracic aortic injury (RESCUE trial). J Vasc Surg. 2013; 57:899-905.e1.

15. Azizzadeh A, Keyhani K, Miller CC 3rd, Coogan SM, Safi HJ, Estrera AL. Blunt traumatic aortic injury: initial experience with endovascular repair. J Vasc Surg. 2009;49:1403-8.

16. Baker SP, O'Neill B, Haddon W Jr, Long WB. The injury severity score: a method for describing patients with multiple injuries and evaluating emergency care. J Trauma. 1974; 14:187-96.

17. Buz S, Zipfel B, Mulahasanovic S, Pasic M, Weng Y, Hetzer R. Conventional surgical repair and endovascular treatment of acute traumatic aortic rupture. Eur J Cardiothorac Surg. 2008;33:143-9.

18. Dake MD, White RA, Diethrich EB, Greenberg RK, Criado FJ, Bavaria JE, et al. Report on endograft management of traumatic thoracic aortic transections at 30 days and 1 year from a multidisciplinary subcommittee of the Society for Vascular Surgery Outcomes Committee. J Vasc Surg. 2011;53:1091-6.

19. Hoffer EK, Forauer AR, Silas AM, Gemery JM. Endovascular stent-graft or open surgical repair for blunt thoracic aortic trauma: Systematic review. J Vasc Interv Radiol. 2008;19:1153-64.

20. Leurs LJ, Bell R, Degrieck Y, Thomas S, Hobo R, Lundbom J, et al. Endovascular treatment of thoracic aortic diseases: combined experience from the EUROSTAR and United Kingdom Thoracic Endograft registries. J Vasc Surg. 2004;40:670-9; discussion 679-80.
21. Forbes TL, Harris JR, Lawlor DK, Derose G. Aortic dilatation after endovascula repair of blunt traumatic thoracic aortic injuries. J Vasc Surg. 2010;52:45-8.

22. Mettler FA Jr, Huda W, Yoshizumi TT, Mahesh M. Effective doses in radiology and diagnostic nuclear medicine: a catalog. Radiology. 2008;248: 254-63.

23. National Research Council (US). Committee to Assess Health Risks from Exposure to Low Level of Ionizing Radiation. Health Risks from Exposure to Low Levels of Ionizing Radiation: BEIR VII Phase 2. Washington, DC: National Academies Press; 2006. 8. Available at: http://www.nap.edu/download.php? record_id $=11340$.

24. Miller LE. Potential long-term complications of endovascular stent grafting for blunt thoracic aortic injury. ScientificWorldJournal. 2012;2012:897489.

25. Rimon U, Shinfeld A, Gayer G. Traumatic injury of the thoracic aorta treated with stent-graft: Is long-term ct angiography follow-up justified? Clin Radiol. 2014;69:e207-10.

26. Reich HJ, Margulies DR, Khoynezhad A. Catastrophic outcome of de-novo aortic thrombus after stent grafting for blunt thoracic aortic injury. Ann Thorac Surg. 2014;98:e139-41.

27. Khoynezhad A, White RA. Pathogenesis and management of retrograde type a aortic dissection after thoracic endovascular aortic repair. Ann Vasc Surg. 2013;27:1201-6

28. Osgood MJ, Heck JM, Rellinger EJ, Doran SL, Garrard CL III, Guzman RJ, et al Natural history of grade I-II blunt traumatic aortic injury. J Vasc Surg. 2014;59: $334-41$.

\title{
EDITORIAL COMMENTARY
}

\section{"RESCUE me": Sweet music for patients with aortic transection}

\author{
Grayson H. Wheatley III, MD
}

See related article on pages 155-61.

The treatment paradigm for blunt thoracic aortic injury (BTAI) has evolved rapidly during the last several years as a result of the introduction of new endovascular aortic stent-graft options. In this issue of the Journal of Thoracic and Cardiovascular Surgery, Khoynezhad and colleagues ${ }^{1}$ report the 1-year results of the RESCUE trial involving thoracic endovascular aortic repair for BTAI with the Valiant Captivia Thoracic Stent-Graft System (Medtronic, Inc, Minneapolis, Minn). From 2010 to 2012, a total of 50 patients were enrolled across 20 sites. The 30 -day outcomes were previously reported, ${ }^{2}$ and this report details the 1-year

\footnotetext{
From the Division of Cardiovascular Surgery, Temple University School of Medicine, Philadelphia, Pa.

Disclosures: Author has nothing to disclose with regard to commercial support.

Received for publication Sept 23, 2014; accepted for publication Sept 25, 2014; available ahead of print Oct 18, 2014.

Address for reprints: Grayson H. Wheatley III, MD, Temple University School of Medicine, 3401 N Broad St, 3rd Floor, Zone C, Suite 301, Philadelphia, PA 19147 (E-mail: grayson.wheatley@tuhs.temple.edu).

J Thorac Cardiovasc Surg 2015;149:161-2

0022-5223/\$36.00

Copyright (c) 2015 by The American Association for Thoracic Surgery

http://dx.doi.org/10.1016/j.jtcvs.2014.09.089
}

follow-up of this cohort of patients to further understanding of the outcomes beyond the 30-day treatment window.

One of the unresolved issues related to endovascular treatment of BTAI is the management of the left subclavian artery (LSA). In this study, $40 \%$ of the patients $(20 / 50)$ had the LSA totally covered with an aortic stent-graft; in another $18 \%$ (9/50), the LSA was partially covered. Three patients required elective LSA bypass because of left arm claudication on days 8,36 , and 103 . There were no stroke-related or other ischemia-related events, and all patients had successful resolution of left arm claudication. This provides valuable insight into how best to handle the LSA when it is totally covered. Although this issue remains subject to controversy, Khoynezhad and colleagues ${ }^{1}$ document that no serious adverse events happened in this subset of patients relating to covering the LSA. Frequently, patients with BTAI have other serious medical and surgical issues and cannot immediately tolerate LSA bypass. With the RESCUE trial data, it can be inferred that many of these patients can undergo LSA bypass at a later time if the clinical need arises. In the absence of a double-blinded, prospective, randomized trial on this topic, the results of this trial will be useful.

Current guidelines recommend endovascular repair of grade II and higher injuries and of grade I BTAI in patients with head injuries for whom elevated cerebral perfusion 


\section{APPENDIX E1. DETAILS OF THE PATIENTS WHO DIED}

\section{Patient 018-001 Died on Day 1 (ISS, 30; Grade III Aortic Injury)}

A 22-year-old man was thrown from a horse into a tree and sustained BTAI, bilateral hemothoraces, and a cardiac contusion. TEVAR was performed promptly on the same day. The patient died the following day from the severe right-sided hemothorax caused by a probable pulmonary vein injury. No additional aortic injury was found at autopsy. However, the independent CEC adjudicated death as related to the aortic injury, but unrelated to the device or procedure.

\section{Patient 182-001 Died on Day 1 (ISS, 50; Grade III Aortic Injury)}

A 68-year-old male pedestrian was struck by a motorcycle and sustained BTAI and a head injury. TEVAR was performed promptly on the same day and was successful, but the patient died the following day from an unrelated cause. The CEC adjudicated death to be unrelated to the aortic injury, device, or the procedure.

\section{Patient 344-033 Died on Day 5 (ISS, 29; Grade III Aortic Injury)}

A 23-year-old man sustained BTAI in a motorcycle crash and multiple other injuries, including a right hemopneumothorax, deformities in both legs, and multiple fractures of the femur. TEVAR was performed promptly on the same day and was successful, but the patient died on day 5 from cardiac arrhythmia. The CEC adjudicated death as unrelated to the aortic injury, device, or procedure.

\section{Patient 059-002 Died on Day 22 (ISS, 34; Grade III Aortic Injury)}

A 67-year-old woman sustained a BTAI in a motor vehicle accident with multiple other injuries, including a distal dissection extending into the abdominal aorta, bilateral hemothoraces, a fractured occipital condyle, subarachnoid hemorrhage, T1 spinal fracture, and a liver laceration, among other abdominal injuries. TEVAR was performed promptly on the same day and was successful, with no endoleaks and some perfusion into the false lumen of the abdominal aorta. Follow-up CT imaging before discharge confirmed no endoleak. The patient had a history of atrial fibrillation and recent pulmonary embolus on subtherapeutic warfarin. The patient was discharged 1 week after the procedure to an acute care facility. The patient died on day 22 of unexplained causes. No autopsy was performed so the cause of death could not be established. The CEC conservatively adjudicated death as related to the aortic injury, device, or procedure because of the limited clinical data available.

\section{Patient 339-003 Died on Day 59 (ISS, 38, Grade III Aortic Injury)}

A 76-year-old man sustained a BTAI in a motor vehicle accident. The patient sustained several injuries including an aortic injury, multiple bilateral rib fractures, facial bone fractures, possible skull fracture and subarachnoid hemorrhage, lung contusions, left femoral acetabular fracture/dislocation, and other multiple pelvic fractures. TEVAR was performed promptly on the same day and was successful. Pertinent medical history included congestive heart failure, atrial fibrillation, anticoagulant therapy, anemia, chronic obstructive pulmonary disease, and lung cancer, for which he was receiving chemotherapy and radiation therapy. A tracheostomy was performed 5 days after the procedure because he was unable to breathe independently. A percutaneous endoscopic gastrostomy tube was placed for nutritional support and he was discharged to a specialty care facility on day 14 . The patient remained nonambulatory and could not be weaned from ventilation, later developing encephalopathy of unclear origin and fevers. Antibiotics were adjusted accordingly. Follow-up chest radiography was performed on day 39 and the device was observed to be intact and stable, although endoleak could not be assessed. The patient's family decided to withdraw treatment and provide comfort measures; ventilation and other treatment ceased, and the patient died later that day (day 59), with cause of death attributed to respiratory failure secondary to pneumonia and underlying chronic obstructive pulmonary disease and lung cancer exacerbated by the motor vehicle accident. The CEC adjudicated the death to be unrelated to the device, procedure or the aorta.

\section{Patient 340-004 Died on Day 169 (ISS, 38; Grade III Aortic Injury)}

A 74-year-old woman sustained a BTAI in a motor vehicle accident. The patient sustained several injuries including head injury, chest and abdominal injuries, and extremity injuries. TEVAR was performed 1 day after the injury with successful implantation of 2 stent grafts. On day 24 , the patient was moved to an acute care facility. Four months later, she was admitted to the emergency room with significant leukocytosis and bowel ischemia secondary to bowel obstruction, at which point the family decided on a do not resuscitate order. The cause of death was reported by the site to be infection unrelated to the aorta, procedure, or to the device. The CEC adjudicated the death as unrelated to the aorta, procedure, or to the device.

\section{Patient 325-001 Died on Day 1086 (ISS, 41; Grade III Aortic Injury)}

A 41-year-old man sustained a BTAI in a motor vehicle accident. In addition to an aortic injury; he sustained a right 
hemothorax, a left hemothorax, a small intestine injury, an adrenal injury, bladder rupture, a pelvic fracture, a tibial plateau fracture, an anterior cruciate ligament tear, and anemia of acute blood loss. The acute aortic injury was described as located at the isthmus and further described as an aortic pseudoaneurysm. The patient underwent open reduction with internal fixation of the pelvis and bladder repair and reanastomosis of the small bowel. TEVAR was then performed and was successful. Final angiography revealed successful exclusion of the pseudoaneurysm with no evidence of dissection, perforation, misaligned deployment, kinking or twisting, and no endoleak. No device malfunctions were reported. There were no further postprocedure complications and the patient was discharged to a rehabilitation facility on day 33 after TEVAR. The patient had 1-month, 6-month, 12-month, and 24-month follow-up visits; the device was intact with no evidence of an endoleak, fracture, migration, twisting, kinking, or occlusion. No adverse events were reported. On day 1047, the patient presented to the emergency room after experiencing a seizure. The seizure was presumed to be secondary to brain metastasis from his stage IV prostate cancer. After discussion with the patient and family; the decision was reached that no aggressive therapies or testing would be done and that a do not resuscitate order would be placed. Care and comfort measures were initiated. On day 1048, he was admitted to an inpatient hospice unit for care. On day 1086, the patient died. The Death Certificate identifies the immediate cause of death as recurrent metastatic prostate cancer. No autopsy was performed. The CEC adjudicated the death as unrelated to the device, procedure, or the aorta.

\begin{tabular}{lll} 
APPENDIX E2 & & \\
\hline \multicolumn{1}{c}{ Principal investigator } & \multicolumn{1}{c}{ Site } & City \\
\hline Robert Allen, MD & Presbyterian Hospital & Charlotte, NC \\
Ali Azizzadeh, MD & Memorial Hermann Heart and Vascular Institute & Houston, Tex \\
Clifford J. Buckley, MD & Scott and White Memorial Hospital & Temple, Tex \\
François Dagenais, MD & Institut Universitaire de Cardiologie et de Pneumologie de Québec & Québec City, Québec \\
Robert J. Feezor, MD & University of Florida & Gainesville, Fla \\
William D. Jordan, MD & University of Alabama Hospital & Birmingham, Ala \\
Robert Hieb, MD & Medical College of Wisconsin Froedtert Hospital & Milwaukee, Wis \\
G. Chad Hughes, MD & Duke University Medical Center & Durham, NC \\
Ali Khoynezhad, MD, PhD & Cedars-Sinai Medical Center & Los Angeles, Calif \\
Joseph V. Lombardi, MD & Cooper Health System & Camden, NJ \\
Alan H. Matsumoto, MD & University of Virginia Medical Center & Charlottesville, Va \\
Ernest Moore, MD & Denver Heath & Denver, Colo \\
Bart E. Muhs, MD & Yale New Haven Hospital & New Haven, Conn \\
Jean M. Panneton, MD & Sentara Norfolk General Vascular \& Transplant Specialists & Norfolk, Va \\
Himanshu J. Patel, MD & Regents of the University of Michigan & Ann Arbor, Mich \\
John P. Pigott, MD & Toledo Hospital Jobst Vascular Center & Toledo, Ohio \\
Joshua Rovin, MD & Cardiac Surgical Associates Bayfront Medical Center & St Petersberg, Fla \\
Marc L. Schermerhorn, MD & Beth Israel Deaconess Medical Center & Boston, Mass \\
Nirman Tulsyan, MD & Vascular Research Institute Morristown Memorial & 1 \\
Omaida C. Velazquez, MD & University of Miami Jackson Memorial Hospital & Morristown, NJ \\
Rodney A. White, MD & Harbor UCLA & Miami, Fla \\
\hline
\end{tabular}


TABLE E1. Anatomic characteristics (core laboratory reported)

\begin{tabular}{lc}
\hline \multicolumn{1}{c}{ Category } & Value \\
\hline Distance from left subclavian artery to injury, $\mathrm{mm}$ & \\
No. & 50 \\
Mean $\pm \mathrm{SD}$ & $15.0 \pm 9.4$ \\
Median (range) & $13.5(0-36)$ \\
Aortic diameter $20 \mathrm{~mm}$ proximal to injury, $\mathrm{mm}$ & \\
No. & 50 \\
Mean $\pm \mathrm{SD}$ & $24.3 \pm 3.9$ \\
Median (range) & $23.5(18-35)$ \\
Maximum descending thoracic artery diameter, mm & \\
No. & 50 \\
Mean \pm SD & $24.3 \pm 3.9$ \\
Median (range) & $23.5(18-35)$ \\
\hline$S D$, Standard deviation.
\end{tabular}

TABLE E2. Secondary procedures ( 3 cases of carotid to subclavian bypass only)*

\begin{tabular}{lllccc}
\hline Days from implant & \multicolumn{1}{c}{ Reason } & Secondary procedure performed & Related to device? & Related to aorta? & Related to procedure? \\
\hline 8 & Peripheral ischemia & Left carotid to subclavian bypass & No & No & Yes \\
36 & Peripheral ischemia & Left carotid to subclavian bypass & No & No & Yes \\
103 & Intermittent claudication & Left carotid to subclavian bypass & No & No & Yes \\
\hline
\end{tabular}

* Only 3 carotid to subclavian secondary procedures were required. Within 1 year, no secondary endovascular reinterventions were performed, nor were there any conversions to open repair. One patient required preoperative carotid to subclavian bypass.

TABLE E3. Details of the adverse events

\begin{tabular}{|c|c|c|c|c|c|}
\hline Patient & Adverse event & $\begin{array}{l}\text { Days after } \\
\text { procedure }\end{array}$ & Serious? & $\begin{array}{c}\text { Related to device, } \\
\text { procedure, or } \\
\text { aortic injury? }\end{array}$ & Action taken \\
\hline \multicolumn{6}{|c|}{ Adverse events $\leq 30 \mathrm{~d}$, related to the device, procedure, or aortic injury } \\
\hline $005-003$ & Focal dissection of the common femoral artery & 0 & Yes & Procedure & Thrombectomy and Dacron patch \\
\hline $340-001$ & Hematoma & 0 & No & Procedure & None \\
\hline $340-004$ & Anoxic brain injury (rupture just before procedure) & 0 & Yes & Aortic injury & Initial stent graft placement \\
\hline $340-004$ & Iliac vein laceration* & 0 & Yes & Procedure & Surgical repair \\
\hline $325-003$ & Erythema at groin incision & 4 & No & Procedure & Medication \\
\hline $325-002$ & Peripheral ischemia & 7 & Yes & Procedure & Carotid to subclavian bypass \\
\hline 112-004 & Arm claudication & 30 & Yes & Procedure & Carotid to subclavian bypass \\
\hline \multicolumn{6}{|c|}{ Additional serious adverse events $>30 \mathrm{~d}$, reported to date, related to the device, procedure, or aortic injury } \\
\hline $344-002$ & Upper limb ischemia & 36 & Yes & Procedure & Carotid to subclavian bypass \\
\hline $325-003$ & Lack of palpable pulse in arm & 39 & No & Procedure & None \\
\hline $340-004$ & Bowel infection (leading to death at $169 \mathrm{~d}$ ) & 167 & Yes & Unrelated & None \\
\hline $5010-002$ & Peripheral Ischemia (calf pain) & 172 & Yes & Procedure & External angioplasty on day 406 \\
\hline
\end{tabular}

*A procedure-related adverse event occurred in patient 340-004 when an angle clamp lacerated the right iliac vein during access. The injury was repaired and the patient recovered. 
TABLE E4. All-cause mortality

\begin{tabular}{lclll}
\hline Patient & $\begin{array}{c}\text { Time to } \\
\text { death, days }\end{array}$ & \multicolumn{1}{c}{$\begin{array}{c}\text { Cause of death, } \\
\text { site reported }\end{array}$} & $\begin{array}{c}\text { Death relatedness, } \\
\text { site reported }\end{array}$ & $\begin{array}{c}\text { Death relatedness, adjudicated by the } \\
\text { Clinical Events Committee }\end{array}$ \\
\hline $018-001$ & 1 & Hemothorax & Not related & Aortic injury \\
$182-001$ & 1 & Traumatic brain Injury & Not related & Not related \\
$344-003$ & 5 & Arrhythmia & Not related \\
$059-002$ & 22 & $\begin{array}{l}\text { Complications of multiple } \\
\text { blunt force injuries }\end{array}$ & $\begin{array}{c}\text { Not evaluable. Device related. Not evaluable. } \\
\text { Aorta related. Not related to procedure }\end{array}$ & Not related \\
& \multicolumn{4}{c}{ Device, procedure, aortic injury } \\
$339-003$ & 59 & Respiratory failure* & Not related & Not related \\
$340-004$ & 169 & Infection & Not related & Not related \\
$325-001$ & 1095 & Seizure $\dagger$ & Not related & Pending adjudication \\
\hline
\end{tabular}

*The 76-year-old man who died on day 59 as a result of respiratory failure had a medical history of atrial fibrillation requiring anticoagulant therapy, congestive heart failure, anemia, chronic obstructive pulmonary disease, and lung cancer and had been receiving chemotherapy and radiotherapy. The motor vehicle accident caused blunt thoracic aortic injury, lung contusions, multiple pelvic fractures, a left femoral acetabular fracture/dislocation, and possible skull fracture and subarachnoid hemorrhage. Total Injury Severity Score, 38 . $\dagger$ The death after a seizure is pending adjudication. 